\title{
Sex dimorphism in ANGIl-mediated crosstalk between ACE2 and ACE in diabetic nephropathy
}

\author{
Sergi Clotet-Freixas ${ }^{1,2} \cdot$ Maria Jose Soler $\mathbb{D}^{1} \cdot$ Vanesa Palau $^{1} \cdot$ Lidia Anguiano $^{1} \cdot$ Javier Gimeno $^{3} \cdot$ Ana Konvalinka $^{2}$. \\ Julio Pascual ${ }^{1} \cdot$ Marta Riera $^{1}$
}

Received: 19 December 2017 / Revised: 25 April 2018 / Accepted: 1 May 2018 / Published online: 8 June 2018

(c) United States \& Canadian Academy of Pathology 2018

\begin{abstract}
Angiotensin-converting enzyme (ACE) and ACE2 play a critical role in the renin-angiotensin system (RAS) by altering angiotensin II (ANGII) levels, thus governing its deleterious effects. Both enzymes are altered by sex and diabetes, and play an important role in the development of diabetic nephropathy (DN). Importantly, previous evidence in diabetic and ACE2deficient (ACE2KO) males suggest a sex-dependent crosstalk between renal ACE and ACE2. In the present work, we aimed to study the sex-specific susceptibility to diabetes and direct infusion of ANGII in kidney disease progression, with a special focus on its link to ACE2 and ACE. In our mouse model, ANGII promoted hypertension, albuminuria, reduced glomerular filtration, and glomerular histological alterations. ANGII adverse effects were accentuated by diabetes and ACE2 deficiency, in a sex-dependent fashion: ACE2 deficiency accentuated ANGII-induced hypertension, albuminuria, and glomerular hypertrophy in diabetic females, whereas in diabetic males exacerbated ANGII-mediated glomerular hypertrophy, mesangial expansion, and podocyte loss. At the molecular level, ANGII downregulated renal ACE gene and enzymatic activity levels, as well as renin gene expression in ACE2KO mice. Interestingly, male sex and diabetes accentuated this effect. Here we show sex dimorphism in the severity of diabetes- and ANGII-related renal lesions, and demonstrate that ACE2- and ACErelated compensatory mechanisms are sex-specific. Supporting our previous findings, the modulation and ANGII-mediated crosstalk between ACE2 and ACE in DN progression was more evident in males. This work increases the understanding of the sex-specific role of ACE2 and ACE in DN, reinforcing the necessity of more personalized treatments targeting RAS.
\end{abstract}

Diabetes is the leading cause of end-stage renal disease. In addition, patients with diabetes are at high risk for cardiovascular disease, and the development of diabetic kidney

These authors contributed equally: Sergi Clotet, Maria José Soler.

These authors share credit for senior authorship: Julio Pascual, Marta Riera.

Electronic supplementary material The online version of this article (https://doi.org/10.1038/s41374-018-0084-x) contains supplementary material, which is available to authorized users.

Maria Jose Soler

msoler@parcdesalutmar.cat

1 Department of Nephrology, Hospital del Mar - IMIM (Hospital del Mar Medical Research Institute), 08003 Barcelona, Spain

2 Division of Nephrology, University Health Network, Toronto, ON M5G 2N2, Canada

3 Department of Pathology, Hospital del Mar - IMIM (Hospital del Mar Medical Research Institute), 08003 Barcelona, Spain disease substantially increases their risk for morbidity and mortality [1, 2]. Chronic effects of hyperglycemia on inducing tissue injury occur via alterations of several mechanisms [3-6]. Among them, dysregulation of the renin-angiotensin system (RAS) plays a critical role in the context of diabetes and hypertension [7-9]. RAS is an important regulator of the cardiovascular and renal function, and angiotensin II (ANGII) is considered its main molecular effector [10]. ANGII induces endothelial lesion, blood pressure (BP) increase, and hypertrophy [11] through its receptors in the renal vasculature, glomeruli, and tubules $[12,13]$. Increases in glomerular ANGII are associated to hypertension, mesangial expansion, glomerular filtration rate (GFR) alterations, glomerulosclerosis, albuminuria, and podocyte loss $[14,15]$. In the tubulointerstitium, ANGII stimulates tumor growth factor (TGF- $\beta$ )-induced fibrosis and inflammation, leading to apoptosis and irreversible lesions [16, 17]. Cumulative evidence supports a deleterious role of angiotensin-converting enzyme (ACE) and a 


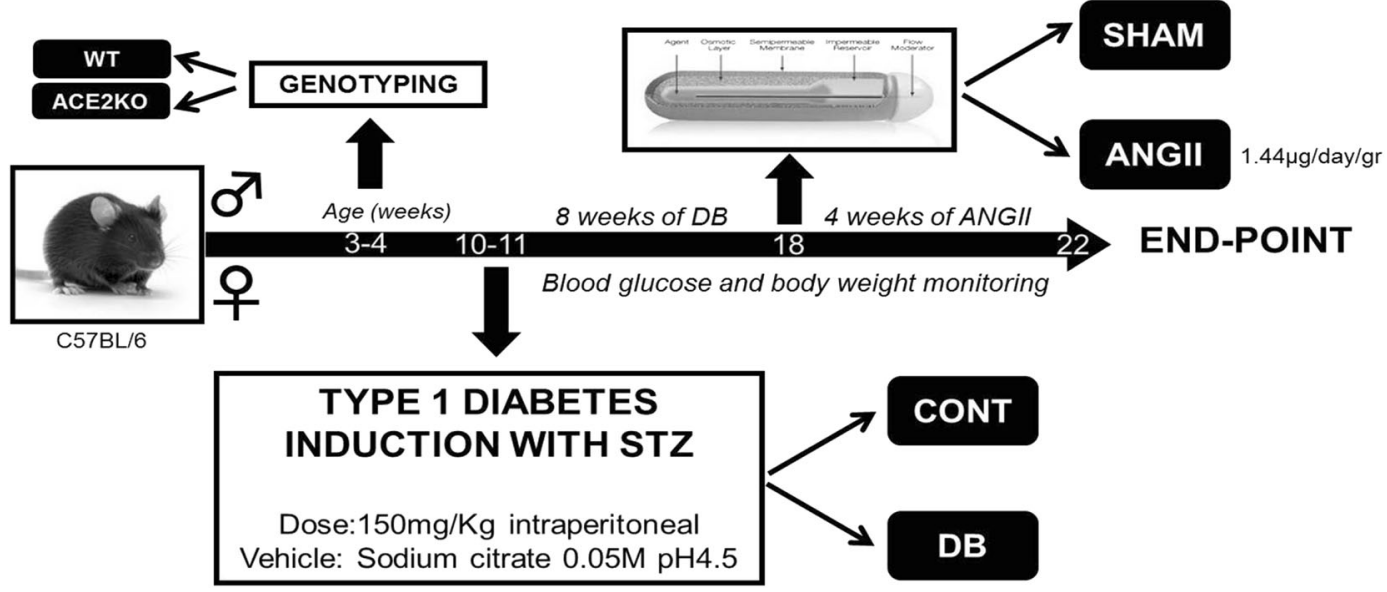

Fig. 1 Timeline diagram that illustrates the experimental design of the study. Male and female mice were genotyped at 3-4 weeks of age, and classified as WT or ACE2KO. Diabetes was induced at 10-11 weeks by a double intraperitoneal injection of $150 \mathrm{mg} / \mathrm{kg}$ of streptozotocin, whereas sodium citrate was administered as vehicle to control groups. After 8 weeks of diabetes, ANGII was infused for 28 days to male and

protective role of ACE2 in the kidney, due to their capacity to produce and degrade ANGII, respectively [18-20].

To prevent the pathological increase in ANGII, pharmacological inhibition of the ANGII axis of RAS is a common therapeutic strategy for treatment of hypertension and diabetic nephropathy (DN) [21]. However, ACE inhibitors and angiotensin-receptor blockers only achieve partial reduction of albuminuria and non-durable suppression of RAS [22]. Importantly, sex differences in renal responses to RAS blockade have been demonstrated [23-26], suggesting that sex-specific changes in the severity of the disease and in RAS might be affecting the efficacy of the treatment.

Among the scientific community there is an increased need for including sex as a biological variable [27-29]. Interestingly, the effect of sex in kidney disease and RAS has recently become the focus of many investigators [30]. Men are at higher risk of hypertension and DN than premenopausal women [26, 31]. Furthermore, previous studies showed sex-specific regulation of RAS in the diabetic kidney and circulation [32, 33]. RAS components such as angiotensinogen (AGT), renin, ACE, and ACE2 are also modulated by castration, suggesting a strong hormonal component $[32,34,35]$ in this sexual dimorphism. We and others have consistently demonstrated upregulation of renal ACE2 and downregulation of renal ACE in diabetes, and proposed these changes as compensatory mechanisms in response to ANGII accumulation [36-39]. In our recent work, we demonstrated that hypertension, kidney injury, and reduction in renal ACE in diabetic male mice were accentuated by ACE2 deficiency and prevented by gonadectomy [18]. These observations suggest that RAS-related female, WT and ACE2KO, control and diabetic mice at a rate of 1.44 $\mu \mathrm{g} / \mathrm{day} / \mathrm{g}$. End-point blood glucose, body weight, kidney weight, heart weight, systolic and diastolic blood pressure, heart rate, urinary albumin excretion, and glomerular filtration rate (GFR) were assessed. Eight to twelve animals per group were included

mechanisms involving ACE and ACE2 modulation are activated in response to ANGII accumulation under pathologic conditions, and that these mechanisms are most likely connected to each other and favored by male sex.

Here we evaluate the effect of sex, diabetes, and ANGII infusion on DN progression, and its relation to the modulation and interaction between ACE2 and ACE. With our findings, we demonstrate that sex differences in DN are related to a sex-specific and ANGII-mediated crosstalk between ACE2 and ACE.

\section{Materials and methods}

\section{Animal model}

Diabetes was induced to 10-week-old wild-type (WT) and ACE2-deficient (ACE2KO), female and male C57BL/6 mice following the high-dose streptozotocin (STZ) Induction Protocol from the Animal Models of Diabetic Complications Consortium with slight modifications [18]. Fourhour-fasted mice were given two intraperitoneal injections of $150 \mathrm{mg} / \mathrm{kg}$ STZ (Sigma) in two consecutive weeks. Citrate buffer was used as vehicle and given to controls. Mice were then followed by 12 weeks of diabetes (Fig. 1). At 8 weeks of follow-up, control and diabetic mice received sham surgery or implantation of an ANGII-loaded mini-osmotic pump (Supplementary Information). ANGII was infused for 28 days (Fig. 1). At the end of the study, end-point blood glucose, body weight (BW), kidney weight $(\mathrm{KW})$, heart weight $(\mathrm{HW})$, systolic and diastolic BP (SBP, DBP), heart rate, urinary albumin excretion (UAE), and 
GFR were assessed, and subsequent molecular studies were performed. Generation of ACE2KO mice has been previously described [18]. Mice were housed ad libitum in ventilated cages. The Ethical Committee of Animal Experimentation at Barcelona Biomedical Research Park (CEEA-PRBB) approved these studies.

\section{Surgical procedure for ANGII infusion}

ANGII at a concentration of $25 \mathrm{mg} / \mathrm{mL}$ in water was sterilized, lyophilized, and stored at $-20^{\circ} \mathrm{C}$ until use. The day previous to the start of ANGII treatment, ANGII was resuspended in $100 \mu \mathrm{L}$ of $0.9 \% \mathrm{NaCl}$ at $0.03654 \mathrm{mg} / \mu \mathrm{L}$. For each animal, a specific volume of ANGII solution was loaded to an osmotic pump (ALZET \#1004) to achieve an infusion rate of $1.44 \mu \mathrm{g} / \mathrm{day} / \mathrm{g} \mathrm{BW}$ of ANGII during 28 days. Once the animals were anesthetized, activated osmotic pumps loaded with ANGII were placed into the subcutaneous space.

\section{Physiological parameters}

Fasting blood samples from the caudal vein were obtained for glucose levels measurements with a glucometer system (ACCU-CHEK, Roche). Mice were considered diabetic when blood glucose levels higher than $250 \mathrm{mg} / \mathrm{dL}$.

SBP, DBP, and heart rate were measured using the CODA $^{\mathrm{TM}}$ mouse tail-cuff system (Kent Scientific Corporation) as previously described [18]. Values were obtained from conscious-trained mice on five consecutive morning sessions at the end of follow-up. SBP and DBP are expressed in $\mathrm{mm} \mathrm{Hg}$, and heart rate in beats per minute (bpm). UAE was determined using the albumin-tocreatinine ratio (ACR) on morning spot urine collections. Urine albumin and creatinine levels were measured by ELISA (Albuwell M, Exocell) and a colorimetric assay (Creatinine Companion, Exocell), respectively. ACR was calculated and expressed as $\mu \mathrm{g}$ Alb/mg Crea. Mice were anesthetized at the end of the study through a single intraperitoneal (i.p.) injection of sodium pentobarbital (45 mg/kg), and GFR was assessed using clearance kinetics of plasma fluorescein isothiocyanate-inulin after a single bolus injection as previously described [19]. GFR was estimated in 5-8 animals per group and values were expressed as $\mu \mathrm{L} / \mathrm{min} / \mathrm{g}$ of $\mathrm{BW}$.

\section{Histology}

Paraffin blocks were cut at $3 \mu \mathrm{m}$ and deparaffined in xylene and rehydrated through graded alcohols. Sections were stained with periodic acid-Schiff (PAS) and morphometric studies were performed as previously [18, 37, 38]. Quantitative measurements were performed on Image $\mathbf{J}$ software in a blinded fashion. Glomerular tuft area (GTA) and mesangial area (MA) were measured in PAS-stained sections by the Image J software (NIH). Sirius Red staining was performed on $4.5 \mu \mathrm{m}$ kidney sections and tubulointerstitial, periglomerular, and intraglomerular collagen accumulation were semiquantitatively evaluated ( $0-4$ score) in a blinded fashion.

Immunohistochemistry staining was performed for ACE and the podocyte marker WT-1. Antigen retrieval was performed with $0.01 \mathrm{M} \mathrm{Na-citrate,} \mathrm{pH} 6$, on $3 \mu \mathrm{m}$ kidney sections by heating for $5 \mathrm{~min}$ in a pressure cooker. Sections were incubated with rabbit polyclonal anti-WT-1 (1:1000, Santa Cruz Biotechnology) or rabbit polyclonal anti-ACE F940 (1:250, Bioworld). Horseradish peroxidaseconjugated anti-rabbit (EnVision ${ }^{\mathrm{TM}}$, Dako) and anti-rat IgG (1:100, A-5795, Sigma) were used as secondary antibodies. Binding of antibodies was detected using the Liquid $\mathrm{DAB}+$ Substrate Chromogen System (Dako). Slides were counterstained with hematoxylin.

For podocyte number determination, 20 microphotographs of glomeruli were taken at $\times 40$ for each animal. WT-1-positive nuclei per glomeruli were counted in a blinded fashion and referred to total glomerular cell number.

\section{Gene expression}

Renal cortex RNA was isolated from frozen kidney samples using the Tripure Isolation Reagent (Roche). Briefly, 40-50 $\mathrm{mg}$ of cortical renal tissue were homogenized in $800 \mu \mathrm{L}$ of Tripure. One hundred and sixty microliters of chloroform were then added and the mixture was centrifuged at $12,000 \times g$ at $6^{\circ} \mathrm{C}$ for $15 \mathrm{~min}$. Transparent phase was separated and RNA was precipitated by the addition of 400 $\mu \mathrm{L}$ of isopropanol and centrifugation at $12,000 \times g$ at $6{ }^{\circ} \mathrm{C}$ for 15 min. RNA pellet was washed with $75 \%$ ethanol and resuspended with $50 \mu \mathrm{L}$ of MQ-water. One microgram of purified RNA was retrotranscribed (High Capacity cDNA RT Kit, Applied Biosystems). Gene expression for Ace, Agt, Ren, Colla2, Tgfb1, and Mcpl was assessed by real-time quantitative PCR using LightCycler ${ }^{\circledR} 480$ SYBR Green I Master (Roche) as previously [18]. Hprt was used as a housekeeping gene. Primer sequences were synthesized by Sigma-Aldrich and are described in Table S1.

Primer sequences (Sigma) are shown in Table S1.

\section{Preparation of kidney cortical tissue for molecular analysis}

Kidney cortex samples were homogenized in a buffer consisting of $50 \mathrm{mM}$ HEPES, pH 7.4, $150 \mathrm{mM} \mathrm{NaCl}, 0.5 \%$ Triton X-100, $0.025 \mathrm{mM} \mathrm{ZnCl}_{2}, 0.1 \mathrm{mM}$ Pefabloc SC Plus (Roche), and EDTA-free protease inhibitor cocktail tablet (Roche). Protein extracts were clarified by centrifugation at 
$14,000 \times \mathrm{g}$ for $10 \mathrm{~min}$ at $4^{\circ} \mathrm{C}$. Protein concentration was determined using the BCA Protein Assay Kit (Thermo Scientific Pierce ${ }^{\oplus}$.

\section{ACE enzymatic activity}

For ACE activity determination, $2 \mu \mathrm{L}$ of serum or $0.5 \mu \mathrm{g}$ of protein were incubated in duplicate with $73 \mu \mathrm{L}$ of reaction buffer (0.5 M borate buffer and 5.45 M N-hippuryl-His-Leu) for 15 or $25 \mathrm{~min}$ at $37^{\circ} \mathrm{C}$, respectively. Twenty millimolar of $o$-phthalaldehyde was added to the samples and formed a fluorescent adduct with the ACE-catalyzed product L-histidyl-L-leucine. Fluorescence was measured at $\lambda_{\mathrm{ex}} 360 \mathrm{~nm}$ and $\lambda_{\mathrm{em}} 485 \mathrm{~nm}$. ACE enzymatic activity in serum and kidney cortex was expressed as relative fluorescence unit (RFU)/ $\mu \mathrm{L} / \mathrm{min}$ and $\mathrm{RFU} / \mu \mathrm{g} / \mathrm{min}$, respectively.

\section{Statistics}

Statistical analyses between groups were performed by Kruskal-Wallis test (SPSS 18.0). Non-parametric Mann-Whitney tests were used for group-to-group comparisons. Significance was defined when $P<0.05$. Data are expressed as mean \pm SEM.

\section{Data availability}

The data that support the findings of this study are available from the corresponding author upon reasonable request.

\section{Results}

\section{ANGII-induced physiological and renal functional alterations were enhanced by ACE2 deficiency and diabetes in a sex-dependent manner}

As expected, in our model STZ-treated groups showed significant hyperglycemia compared with controls. Diabetes was accompanied by significantly decreased $\mathrm{BW}$ in all the experimental groups (Table 1). All male groups presented higher $\mathrm{BW}$ and $\mathrm{KW}$ than females. Interestingly, a significant degree of renal hypertrophy in terms of KW/BW was observed in diabetic WT males, but not in diabetic WT females. In these WT groups, HW was also significantly higher in males than in females.

ANGII induced cardiac hypertrophy as judged by the increased HW/BW ratio in all groups. In males, this increase was significant in control groups, regardless of the genotype. In females, however, significant ANGII-related cardiac hypertrophy was observed only in ACE2KO mice (Table 1). Ace 2 deletion induced a decrease in BW, which was significant only in males. In contrast, ACE2 deficiency significantly accentuated renal hypertrophy only in diabetic females (Table 1).

ANGII increased SBP and DBP in all groups (Fig. 2a, b). In females, the ANGII-associated increase in BP was significantly accentuated by diabetes and ACE2 deficiency. Control and diabetic ACE2KO females presented significantly higher SBP and DBP than the WT. In contrast, ANGII-induced hypertension to a similar extent in all male groups (Fig. 2a, b). Heart rate was significantly decreased by diabetes in ACE2KO females. In males, decreased heart rate was also promoted by ANGII in the context of diabetes or ACE2 deficiency (Fig. 2c).

ANGII induced an increase in UAE in all non-diabetic groups, and accentuated albuminuria in all diabetic groups (Fig. 2d). In females, ACE2 deficiency significantly accentuated the ANGII-induced increase in UAE. In males, the proalbuminuric effect of ANGII was comparable between WT and ACE2KO. After 12 weeks of diabetes WT males showed significantly higher UAE than females, and ANGII infusion accentuated these effects. Interestingly, these differences disappeared in the ACE2KO groups. ANGII-induced albuminuria was accompanied by decreased GFR in all groups, except for diabetic males (Fig. 2e). In this regard, diabetic males showed higher GFR values than diabetic females, and this difference was significant in the setting of ANGII infusion, indicating a higher degree of hyperfiltration in the diabetic male kidney under exposure to ANGII (Fig. 2e).

\section{ANGIl-induced histological renal alterations were accentuated by the loss of ACE2 and diabetes in a sex-dependent manner}

In WT females, ANGII and diabetes significantly decreased percentage of podocytes. In WT males, diabetes only caused a slight diminution in the percentage. ANGII decreased the percentage of podocytes in all male groups, but this diminution was only significant in the setting of diabetes and ACE2 deficiency (Fig. 3a, b). Surprisingly, in ACE2KO females, ANGII significantly increased this percentage (Fig.3a, b).

ANGII and diabetes increased GTA (Fig. 3c, e). In females, ANGII infusion, diabetes, and ACE2 deficiency were associated to higher GTA, especially when these pathological settings were combined in diabetic and ANGII-infused ACE2KO females. In males, increased GTA by diabetes was observed in ANGII-infused, but not in SHAM-operated mice. ANGII significantly increased GTA in diabetic ACE2KO but not WT males. In concordance with GTA, augmented MA due to diabetes was only significant in ANGII-infused males, and ANGII significantly augmented the area of the mesangium in diabetic ACE2KO, but not WT males (Fig. 3d, e). 
Table 1 Physiologic parameters at the end of the study

Physiologic parameters after 12 weeks of type 1 diabetes and 28 days of ANGII infusion

\begin{tabular}{|c|c|c|c|c|c|c|}
\hline Study group & $\mathrm{BG}(\mathrm{mg} / \mathrm{dL})$ & $\mathrm{BW}(\mathrm{g})$ & $\mathrm{KW}(\mathrm{g})$ & $\mathrm{HW}(\mathrm{g})$ & $\mathrm{KW} / \mathrm{BW}(\%)$ & $\mathrm{HW} / \mathrm{BW}(\%)$ \\
\hline F-WT-CONT-SHAM & $172.00 \pm 7.61$ & $25.87 \pm 0.66$ & $0.27 \pm 0.01$ & $0.13 \pm 0.01$ & $1.04 \pm 0.05$ & $0.49 \pm 0.03$ \\
\hline F-WT-CONT-ANGII & $175.17 \pm 7.05$ & $25.13 \pm 0.92$ & $0.24 \pm 0.01^{\$}$ & $0.13 \pm 0.01$ & $0.95 \pm 0.03$ & $0.54 \pm 0.02$ \\
\hline F-WT-DB-SHAM & $306.55 \pm 31.74^{*}$ & $21.24 \pm 0.43^{*}$ & $0.24 \pm 0.02$ & $0.10 \pm 0.01^{*}$ & $1.13 \pm 0.08$ & $0.46 \pm 0.02$ \\
\hline F-WT-DB-ANGII & $389.36 \pm 44.05^{*}$ & $20.83 \pm 0.27^{*}$ & $0.23 \pm 0.01$ & $0.10 \pm 0.01^{*}$ & $1.09 \pm 0.07$ & $0.49 \pm 0.03$ \\
\hline F-ACE2KO-CONT-SHAM & $177.00 \pm 11.77$ & $24.40 \pm 0.57$ & $0.23 \pm 0.01$ & $0.12 \pm 0.01$ & $0.93 \pm 0.06$ & $0.50 \pm 0.02$ \\
\hline F-ACE2KO-CONT-ANGII & $157.30 \pm 8.07$ & $23.28 \pm 0.46$ & $0.23 \pm 0.01$ & $0.15 \pm 0.01^{\$}$ & $1.00 \pm 0.04$ & $0.65 \pm 0.03^{\$ \dagger}$ \\
\hline F-ACE2KO-DB-SHAM & $354.30 \pm 46.83^{*}$ & $20.24 \pm 0.65^{*}$ & $0.27 \pm 0.02$ & $0.10 \pm 0.01^{*}$ & $1.34 \pm 0.10^{* \dagger}$ & $0.50 \pm 0.03$ \\
\hline F-ACE2KO-DB-ANGII & $436.78 \pm 51.50^{*}$ & $19.82 \pm 0.77^{*}$ & $0.26 \pm 0.01$ & $0.12 \pm 0.01^{* \dagger}$ & $1.31 \pm 0.04^{* \dagger}$ & $0.60 \pm 0.02^{\$ \dagger}$ \\
\hline M-WT-CONT-SHAM & $199.67 \pm 9.93$ & $33.33 \pm 1.02^{\#}$ & $0.36 \pm 0.02^{\#}$ & $0.17 \pm 0.01^{\#}$ & $1.09 \pm 0.05$ & $0.50 \pm 0.04$ \\
\hline M-WT-CONT-ANGII & $158.11 \pm 7.97^{\$}$ & $31.79 \pm 1.06^{\#}$ & $0.35 \pm 0.02^{\#}$ & $0.19 \pm 0.01^{\#}$ & $1.10 \pm 0.07$ & $0.61 \pm 0.02^{\$}$ \\
\hline M-WT-DB-SHAM & $492.13 \pm 41.44^{* \#}$ & $27.62 \pm 0.66^{* \#}$ & $0.35 \pm 0.02^{\#}$ & $0.13 \pm 0.01^{* \#}$ & $1.27 \pm 0.07^{*}$ & $0.47 \pm 0.04$ \\
\hline M-WT-DB-ANGII & $554.33 \pm 16.76^{* \#}$ & $26.17 \pm 0.78^{* \#}$ & $0.34 \pm 0.03^{\#}$ & $0.14 \pm 0.01^{* \#}$ & $1.31 \pm 0.12^{\#}$ & $0.55 \pm 0.04$ \\
\hline M-ACE2KO-CONT-SHAM & $175.50 \pm 9.72$ & $28.06 \pm 0.62^{\dagger \#}$ & $0.28 \pm 0.02^{\dagger \#}$ & $0.13 \pm 0.01^{\dagger}$ & $1.00 \pm 0.07$ & $0.45 \pm 0.04$ \\
\hline M-ACE2KO-CONT-ANGII & $165.75 \pm 11.19$ & $27.79 \pm 0.58^{\dagger \#}$ & $0.31 \pm 0.02^{\dagger \#}$ & $0.17 \pm 0.01^{\$ \dagger}$ & $1.10 \pm 0.04$ & $0.60 \pm 0.03^{\$}$ \\
\hline M-ACE2KO-DB-SHAM & $494.25 \pm 48.16^{*}$ & $24.72 \pm 0.99 * \pitchfork \#$ & $0.32 \pm 0.02$ & $0.12 \pm 0.01^{\#}$ & $1.40 \pm 0.10^{*}$ & $0.50 \pm 0.02$ \\
\hline M-ACE2KO-DB-ANGII & $570.13 \pm 20.21^{*}$ & $23.10 \pm 0.83^{* \hbar \#}$ & $0.30 \pm 0.01^{\#}$ & $0.13 \pm 0.00^{*}$ & $1.29 \pm 0.04^{*}$ & $0.57 \pm 0.02$ \\
\hline
\end{tabular}

$B G$ blood glucose, $B W$ body weight, $K W$ kidney weight, $H W$ heart weight and the corresponding ratios KW/BW and $\mathrm{HW} / \mathrm{BW}$ after 12 weeks of T1DM, and 28 days of ANGII infusion, $F$, female, $M$ male, $C O N T$, control, $D B$ diabetic, WT wild type, ACE2KO ACE2 knockout, ANGII angiotensin II-infused. Values are expressed as means \pm SEM $(n=8-12$ per group)

${ }^{\$} P<0.05$ vs. SHAM; ${ }^{*} P<0.05$ vs. CONT; ${ }^{\dagger} P<0.05$ vs. WT; ${ }^{\#} P<0.05$ vs. female

\section{ANGII-induced fibrosis and inflammation was enhanced by loss of ACE2 and diabetes in a sex- dependent manner}

ANGII showed a sex-specific profibrotic and proinflammatory effect in our model. In females, ANGII significantly accentuated the increase in cortical $T g f b l$ gene expression associated to diabetes in WT, but not ACE2KO mice (Fig. 4a). In males, ANGII up-regulated $T g f b l$ in the WT groups, and significantly downregulated $T g f b 1$ and Coll $\alpha 2$ in the diabetic ACE2KO (Fig. 4a, b). ANGII stimulated the gene expression of cortical Mcpl in non-diabetic mice, and enhanced its increase in the diabetic kidney (Fig. 4c). At the protein level, diabetes increased tubulointerstitial collagen deposition in all groups (Fig. 4d, g). Male sex was associated to greater accumulation of periglomerular and intraglomerular collagen fibers (Fig. 4e, f). In females, ANGII-infused groups showed a trend towards higher periglomerular and intraglomerular collagen levels, especially in the setting diabetes and ACE2 deficiency (Fig. 4e, f).

\section{Loss of ACE2 accentuated ANGII-mediated downregulation of ACE in diabetic male mice}

Aiming to evaluate the crosstalk between ACE2 and ACE in our animal model, we next examined the sex differences in the modulation of ACE by ANGII and diabetes, and how these differences were affected by the absence of ACE2.

We found that ANGII significantly modulated circulating ACE activity in males, but not females (Fig. 5a). Indeed, a significant decrease in serum ACE was observed when ANGII was administered to diabetic male mice. Importantly, this ANGII-induced reduction in circulating ACE was also observed in the setting of ACE2 deficiency, and was more pronounced in diabetic ACE2KO males, which showed the lowest values across all male groups (Fig. 5a). In females, diabetes and Ace 2 deletion significantly increased circulating ACE, but these changes were not altered by the infusion of ANGII.

In the kidney cortex, lower ACE activity and protein expression was observed in the majority of experimental groups receiving ANGII, as compared to their SHAM groups(Fig. 5b, c). In particular, a more pronounced and significant decrease in renal ACE was observed in ACE2KO-DB males, which also presented significant lower values of ACE activity as compared to the female groups (Fig. 5b). This observation was reinforced by the immunostaining pattern for renal ACE, as positive ACE staining in the tubular brush border was almost absent in ACE2KO-DB-ANGII males (Fig. 5c). 
A

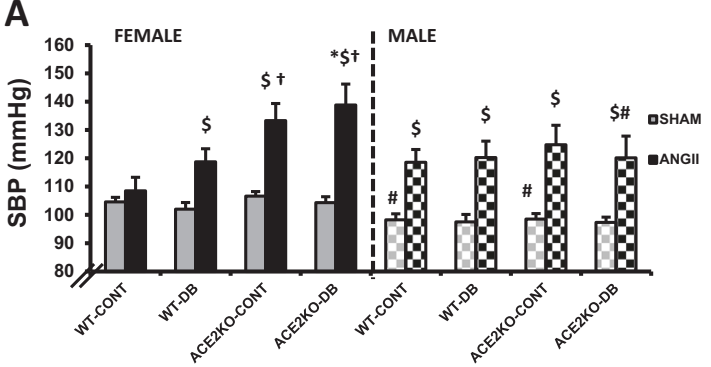

C

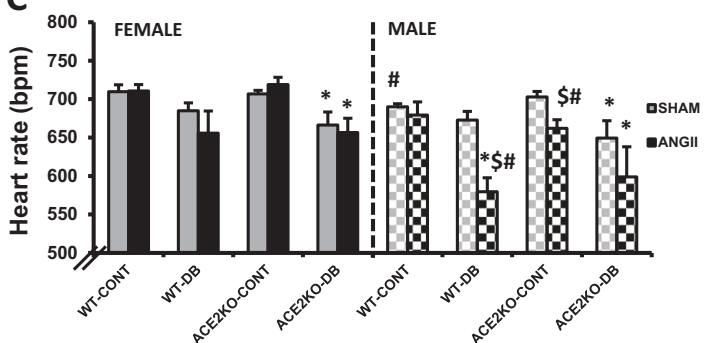

E

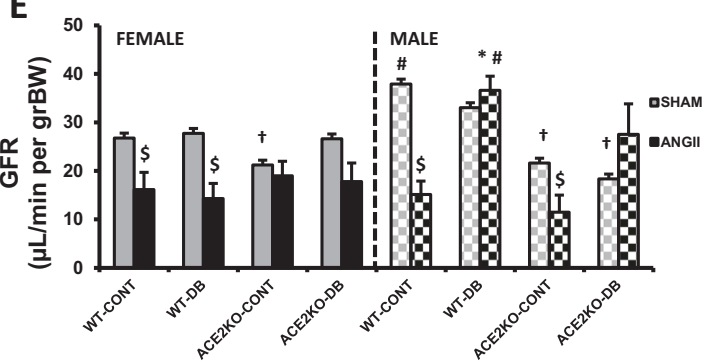

Fig. 2 Influence of ANGII infusion, diabetes, Ace 2 deletion, and sex on renal hemodynamics and glomerular function. Sex differences on the effect of Ace 2 deletion on SBP (a), DBP (b) heart rate (c), UAE (d), and GFR (e) were studied after 12 weeks of diabetes and 28 days of ANGII infusion. For these experiments, 5 to 12 animals were analyzed in each group. Data are expressed as mean \pm SEM. ${ }^{\$} P<0.05$

\section{ANGII-mediated negative feedback regulation of the AGT-renin-ACE axis was enhanced by loss of ACE2 and diabetes in a sex-dependent manner}

In line with protein and activity data, ANGII infusion was associated to lower Ace expression (Fig. 6a). Within the diabetic groups, ANGII-mediated Ace downregulation was more pronounced in ACE2KO males, which presented the lowest expression values among all groups (Fig. 6a). Similarly, ANGII significantly decreased Ren expression in all groups. ACE2KO-CONT-SHAM females presented significantly lower Ren than WT-CONT-SHAM. In males, diabetes and ACE2 deficiency accentuated ANGII effects on diminishing Ren. Indeed, ACE2KO-DB-ANGII males also had the lowest Ren expression among all groups (Fig. 6b).

ANGII infusion was generally associated to an increase in renal Agt, which was accentuated by diabetes and ACE2 deficiency in a sex-dependent manner. In females, combination of these factors was accompanied by higher $\mathrm{Agt}$
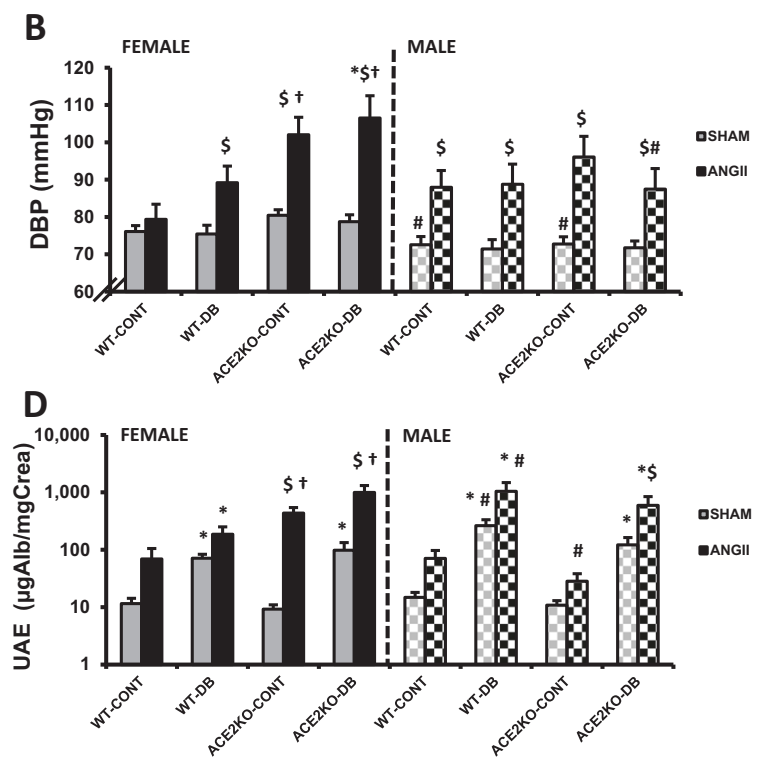

vs. SHAM, ${ }^{*} P<0.05$ vs. non-diabetic controls, ${ }^{\dagger} P<0.05$ vs. WT, ${ }^{\#} P$ $<0.05$ vs. females. CONT control, DB diabetic, WT wild type, ACE2KO Ace 2 knockout, ANGII angiotensin II, SBP systolic blood pressure, DBP diastolic blood pressure, UAE urinary albumin excretion, GFR glomerular filtration rate

expression. In males, ANGII significantly augmented $A g t$ in ACE2KO-CONT mice, and accentuated the diabetesinduced increase in Agt in the ACE2KO-DB (Fig. 6c). Interestingly, females showed higher Agt and Ren expression than males.

\section{Discussion}

Male sex increases the incidence and progression of chronic kidney disease [40]. Previous findings suggest that in diabetes, sex differences are related to sex differences in RAS $[18,41]$. Within this system, imbalanced levels of ACE and ACE2 are related to the progression of hypertensive and diabetic kidney disease [18, 36, 37, 42, 43]. In this work, we demonstrate that in the absence of genetic ACE2 deficiency (WT groups) diabetic male mice exhibited worsened kidney disease progression as compared to diabetic females. In particular, diabetic males showed accentuated glomerular lesions in terms of hyperfiltration, albuminuria, glomerular 
A

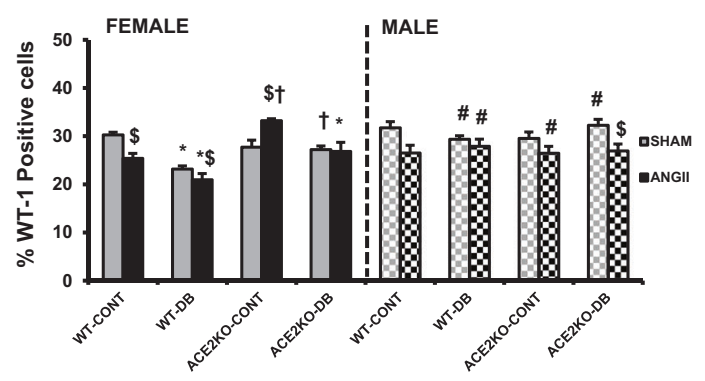

B
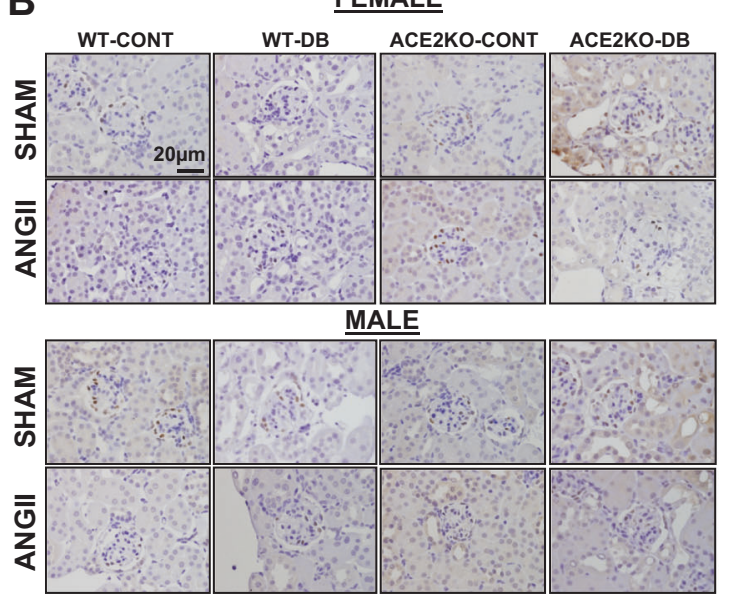

Fig. 3 Influence of ANGII infusion, diabetes, Ace 2 deletion, and sex on podocyte loss and glomerular structural alterations. Podocyte number is represented as the $\%$ of brown positive cells after WT-1 immunostaining (a). Representative photomicrographs depicting glomerular WT-1 staining from all the experimental groups are shown in (b). Sex differences on the effect of Ace 2 deletion on glomerular tuft area (GTA, c) and mesangial area (MA, d) were also studied after 12 weeks of diabetes and 28 days of ANGII infusion. Panel e shows

hypertrophy, and mesangial expansion. In concordance, Costa et al. [32] reported a greater UAE increase in STZ diabetic male rats compared with females. In addition, the presence of hyperfiltration, glomerular hypertrophy, and mesangial matrix expansion has been consistently reported when studying STZ and Akita mice with T1DM [19, 20, 44-48]. These observations strengthen the idea that male sex contributes to more severe alterations on glomerular function and morphology in T1DM.

With our findings, we also demonstrate sex differences in the activation of compensatory mechanisms of RAS, namely the downregulation of the ACE axis, in the sexspecific progression of DN. In diabetic males, ACE2 deletion was accompanied by a pronounced decrease in the levels and activity of ACE, which was not observed in females. The decrease in renal ACE in the diabetic kidney has been described previously $[18,38,40,43]$. We now increased the current knowledge by showing that the
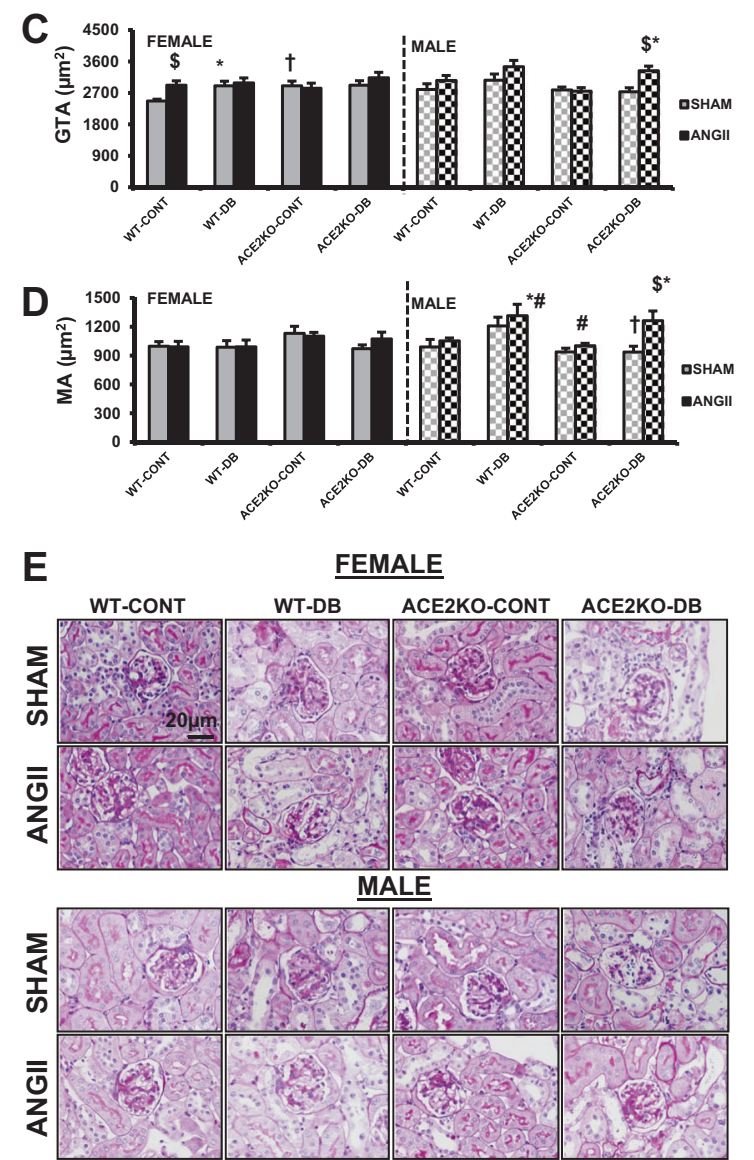

representative photomicrographs depicting glomerular morphometric changes in PAS-stained sections from all the experimental groups. Scale bar $=20 \mu \mathrm{m}$. Original magnification, $\times 40$. For these experiments, 6 to 10 animals were analyzed in each group. Data are expressed as mean \pm SEM. ${ }^{\$} P<0.05$ vs. SHAM, $* P<0.05$ vs. nondiabetic controls (CONT), ${ }^{\dagger} P<0.05$ vs. WT, ${ }^{*} P<0.05$ vs. females. CONT control, DB diabetic, WT wild type, ACE2KO Ace 2 knockout, ANGII angiotensin II, WT-1 Wilms tumor 1

activation of this compensatory mechanism was strongly influenced by sex. However, some of the differences observed might be related to higher glycemia, which was generally seen in male diabetic groups.

ANGII is the common denominator between ACEand ACE2-catalyzed reactions. In line with other authors [34, 49], we previously showed a more accentuated decrease in renal ACE when ANGII accumulation was favored in the absence of ACE2. In addition, the reduction in renal ACE in ACE2-deficient mice was prevented by androgen reduction, suggesting that these ANGII-mediated changes were favored by male sex [18]. In front of these findings, we next hypothesized that direct infusion of ANGII would induce the downregulation of ACE in the male diabetic kidney, and that this effect would be accentuated by male sex and ACE2 deficiency.

ANGII play a crucial role on hypertension and kidney disease by altering renal hemodynamics and promoting 

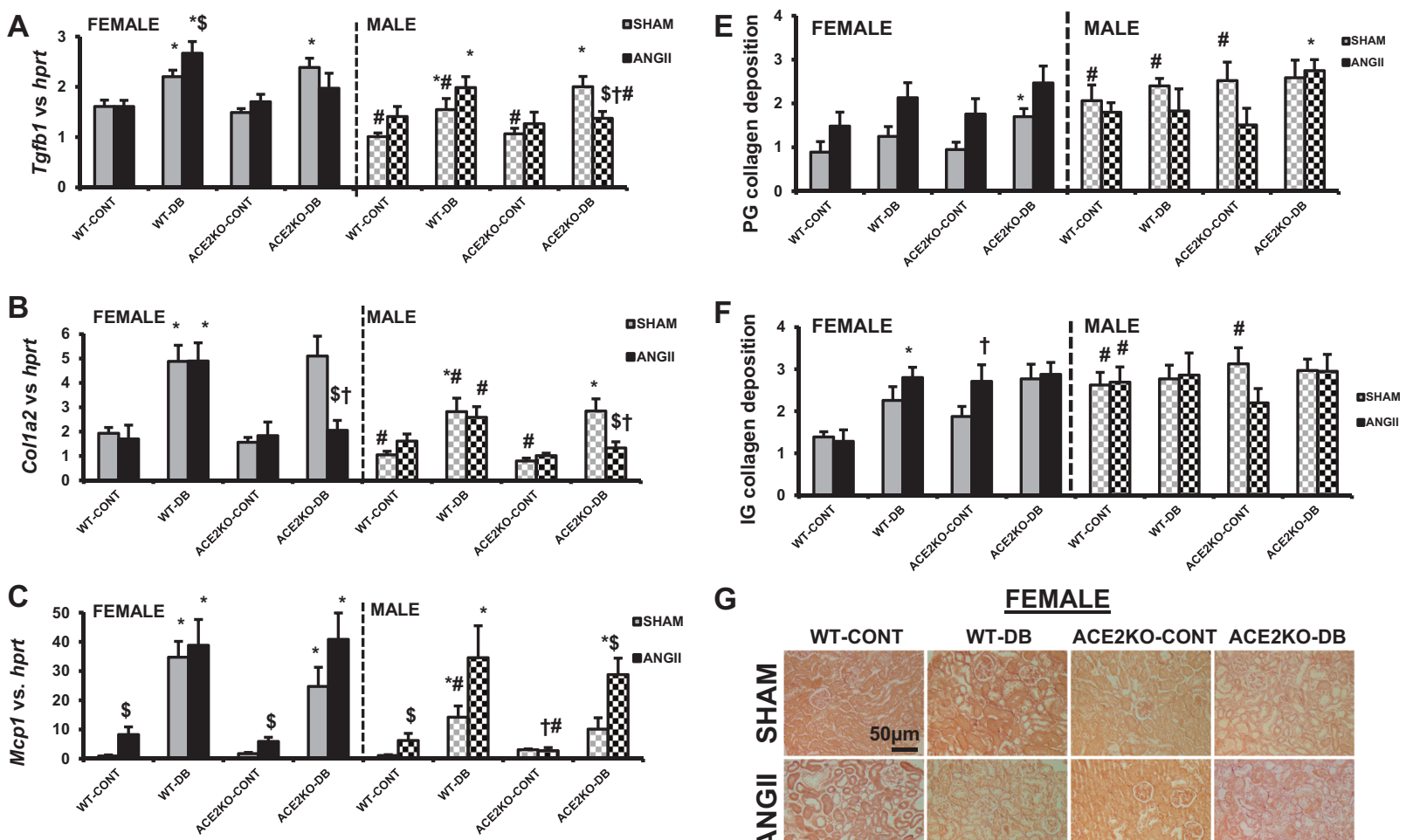

G
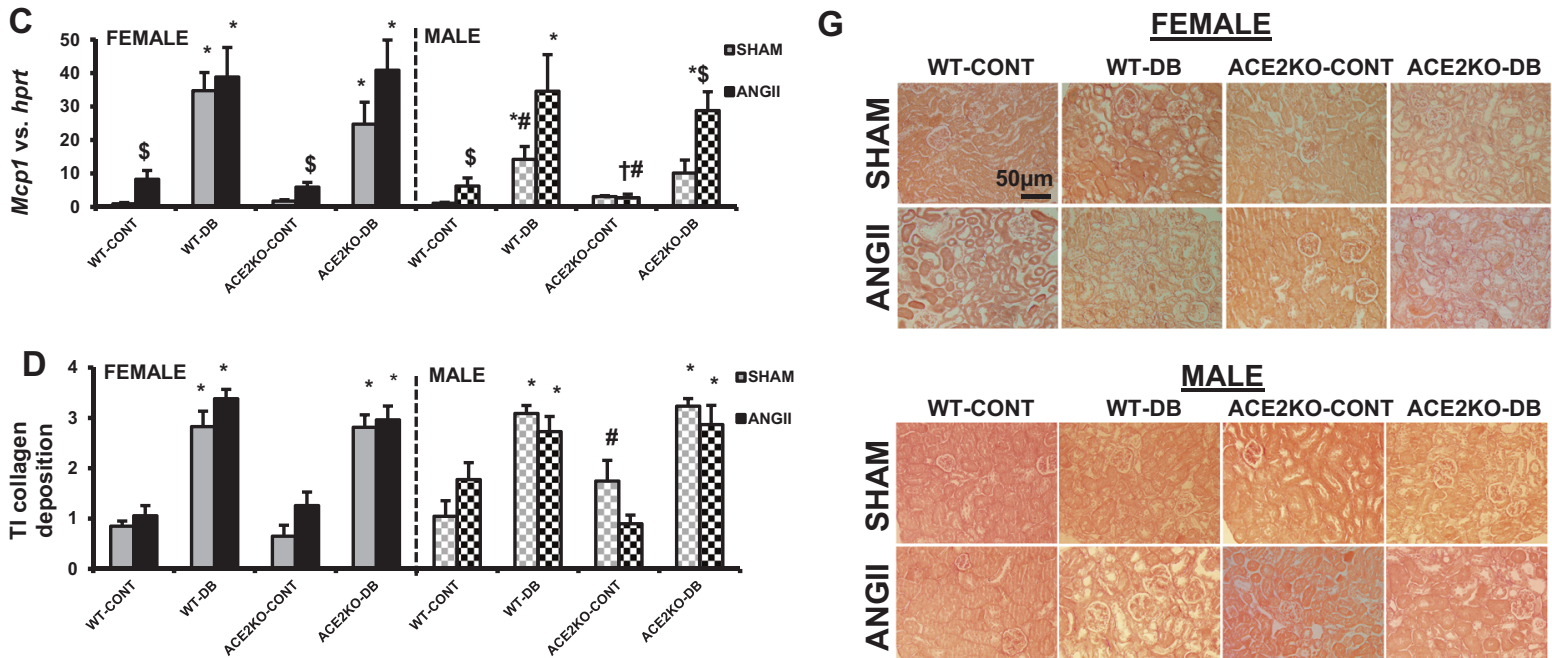

Fig. 4 Influence of ANGII infusion, diabetes, Ace 2 deletion, and sex on renal fibrosis and inflammation markers. Renal cortex mRNA levels were assessed for transforming growth factor beta $(T g f b 1, \mathbf{a})$, collagen I alpha 2 chain $($ Colla2, b), and monocyte chemoattractant protein $(M c p 1, \mathbf{c})$. Values were normalized to Hprt gene expression. Tubulointerstitial (d), periglomerular (e), and intraglomerular (f) collagen deposition was evaluated in a semiquantitative manner (scale $0-4$ ) on Picrosirius red-stained tissue sections. Representative

renal fibrosis and inflammation, among other lesions [50, 51]. These effects are more evident in diabetes, since glomerular and tubular RAS activation and ANGII production are accentuated by hyperglycemia [52]. We now demonstrate that (1) Ace 2 deletion accentuates diabetes- and ANGII-induced alterations in a sex-dependent manner, and (2) sex-specific ANGII actions are related to a different imbalance of RAS involving a regulation of the negative feedback loop of this system, especially in the male diabetic kidney.

The combined effect of ANGII and ACE2 deficiency on $\mathrm{BP}$, cardiac function and vascular injury has been previously studied; however, these studies were performed exclusively in male mice $[53,54]$. We now

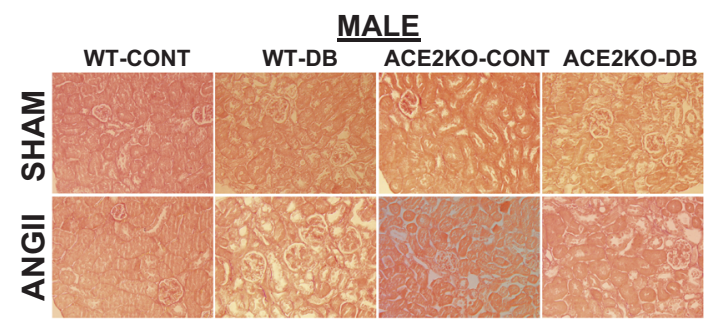

photomicrographs for collagen deposition are shown for all experimental groups $(\mathbf{g})$. Scale bar $=50 \mu \mathrm{m}$. Original magnification, $\times 20$. For these experiments, 5-10 animals were analyzed in each group. Data are expressed as mean \pm SEM. ${ }^{\$} P<0.05$ vs. SHAM, $* P<0.05$ vs. non-diabetic controls (CONT), ${ }^{\dagger} P<0.05$ vs. WT, ${ }^{\#} P<0.05$ vs. females. CONT control, DB diabetic, WT wild type, ACE2KO Ace2 knockout, ANGII angiotensin II, TI tubulointerstitial, PG periglomerular, IG intraglomerular

studied both sexes in the context of ANGII infusion, diabetes, and ACE2 deficiency, and focused our approach on kidney function and histopathology. It is accepted that ANGII promotes cardiac hypertrophy, hypertension, albuminuria, GFR decrease, and tubular injury [55-59]. Here we report a sex dimorphism on these effects. In our non-diabetic WT mice, ANGII promoted hypertension and cardiac hypertrophy in males, which also showed a greater decrease in GFR as compared to females. Growing evidence supports deleterious effects of male sex and female protection against ANGII-related hypertension and deterioration of hemodynamics. In male and ovariectomized female rats, enhanced hypertension and GFR decrease in response to ANGII was observed $[60,61]$. 
A

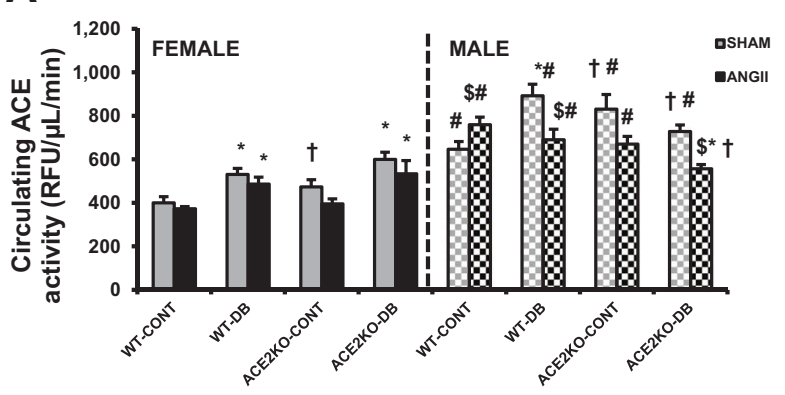

B

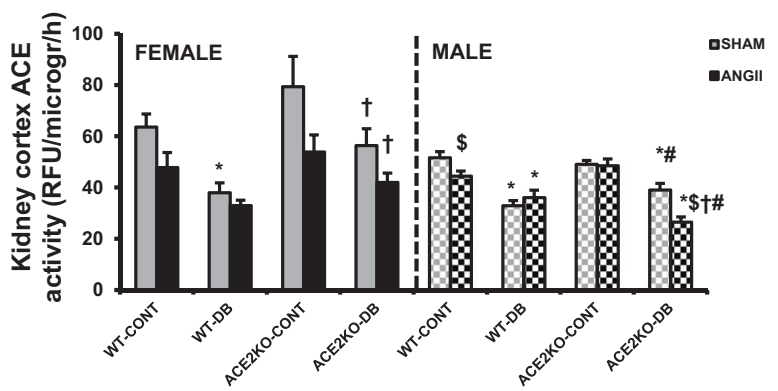

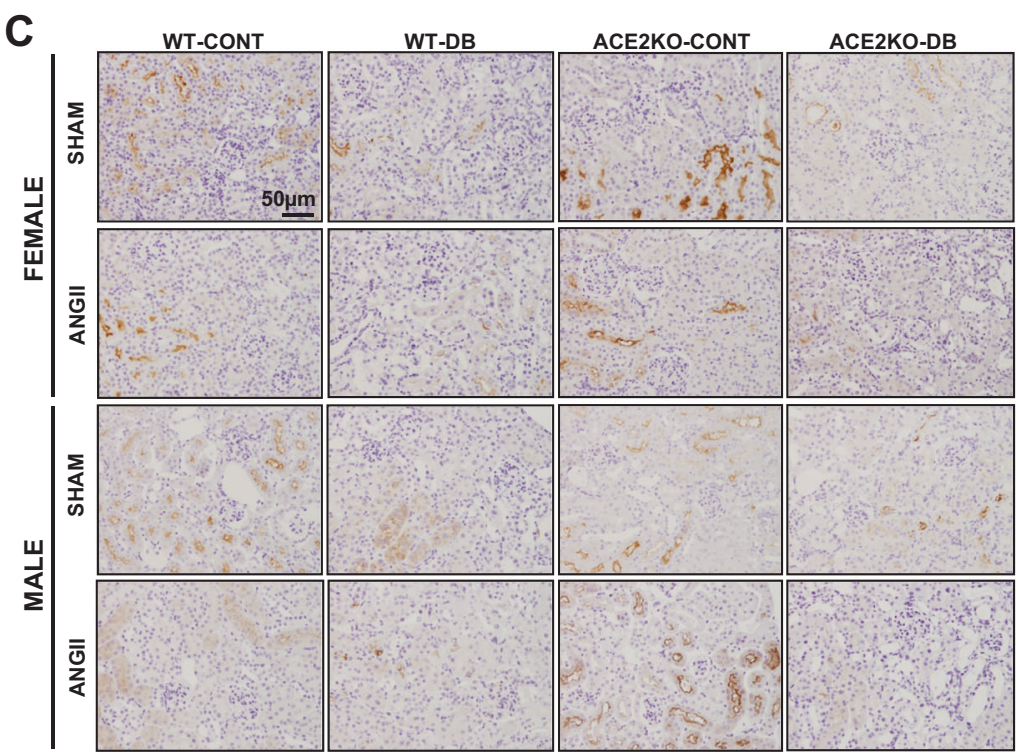

Fig. 5 Influence of ANGII infusion, diabetes, Ace 2 deletion, and sex on circulating and renal ACE. ACE activity was assessed in the serum (a) and the kidney cortex (b) of all experimental groups. Renal ACE protein localization and expression was also assessed by immunohistochemistry $(\mathbf{c})$. Scale bar $=50 \mu \mathrm{m}$. Original magnification, $\times 20$. For these experiments, 6-12 animals were analyzed in each group. Data are expressed as mean \pm SEM. ${ }^{\$} P<0.05$ vs. SHAM, $* P<0.05$ vs. non-diabetic controls (CONT), ${ }^{\dagger} P<0.05$ vs. WT, ${ }^{\#} P<0.05$ vs. females. CONT control, DB diabetic, WT wild type, ACE2KO Ace2 knockout, ANGII angiotensin II, ACE angiotensin-converting enzyme, RFU relative fluorescence units

previous studies showed that ACE2 administration and podocyte-specific overexpression attenuated these alterations in diabetic males $[19,20]$. Our results suggest a sexspecific renoprotective role of ACE2 against ANGIImediated injury.

An important finding of this study is that sex modulates the effect of ANGII and diabetes on RAS. We also demonstrate a sex-specific modulation of the negative feedback loop of RAS in the ANGII-infused, diabetic and ACE2-deficient kidney (Fig. 7). Importantly, downregulation of circulating and renal ACE by infusion of exogenous ANGII was more evident in males, especially in the setting of diabetes and ACE2 deficiency. Indeed, ANGII induced a more marked decrease in renal Ren and Ace expression in ACE2KO diabetic males than females. In agreement, hypertensive mRen2.Lewis males showed a greater decrease in renal renin than females, compared with normotensive rats [42]. 


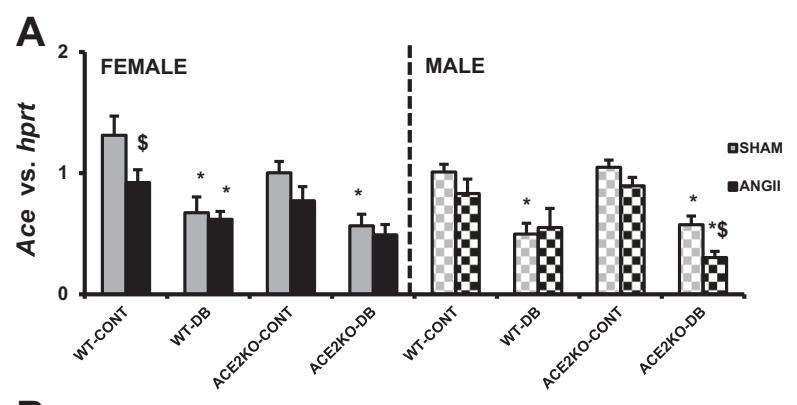

B

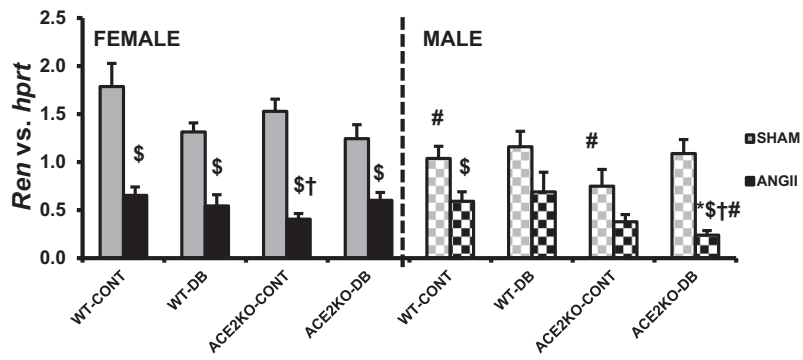

C

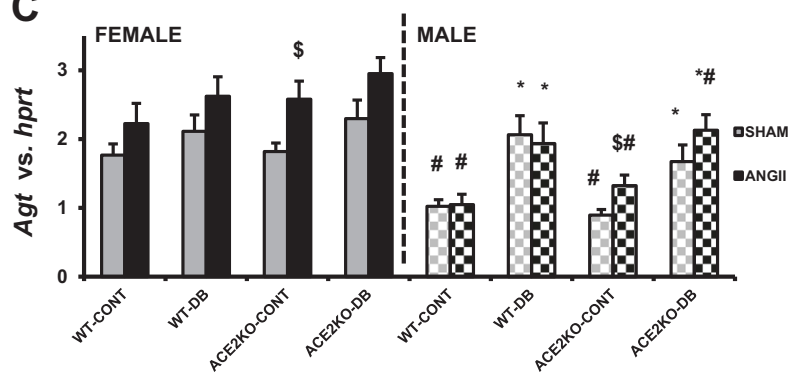

Fig. 6 Influence of ANGII infusion, diabetes, Ace 2 deletion, and sex on the cortical gene expression of RAS components. Renal cortex mRNA levels were assessed for angiotensin-converting enzyme (Ace, a), renin $(R e n, \mathbf{b})$, and angiotensinogen $(A g t, \mathbf{c})$. Values were normalized to Hprt gene expression. For these experiments, 5-8 animals were analyzed in each group. Data are expressed as mean \pm SEM. ${ }^{\$} P<$ 0.05 vs. SHAM, $* P<0.05$ vs. non-diabetic controls (CONT), ${ }^{\dagger} P<$ 0.05 vs. WT, ${ }^{\#} \mathrm{P}<0.05$ vs. females. CONT control, DB diabetic, WT wild type, ACE2KO Ace 2 knockout, ANGII angiotensin II

Our data reinforce the idea of a crosstalk between ACE2 and ANGII-mediated downregulation of ACE. We surmise that ACE downregulation in hypertensive and diabetic ACE2KO males may be an attempt to reduce endogenous ANGII production and counterbalance the harmful effects of exogenous ANGII in the absence of ACE2. In turn, in diabetic and ANGII-infused ACE2KO females, higher renal Ren and Agt levels indicate a different activation of RAS. Together with higher renal ACE at the gene, protein, and activity level, RAS modulation in diabetic, ANGII-infused and ACE2-deficient females suggests a shift of the cascade towards the classic AGT/renin/ACE/ANGII axis. One surmises that this shift would result in enhanced production of endogenous ANGII, and probably explain the worsened hypertension and hemodynamic alterations in diabetic ACE2KO females (Fig. 7). In concordance, STZ-diabetic

\begin{tabular}{|ccccc|}
\hline & \multicolumn{2}{c}{ WT-DB-ANGII } & \multicolumn{2}{c|}{ ACE2KO-DB-ANGII } \\
\hline Hemodynamics and Histology & FEMALE & MALE & FEMALE & MALE \\
\hline Hypertension & $\uparrow$ & $\uparrow$ & $\uparrow \uparrow$ & $\uparrow$ \\
\hline GFR & $\downarrow$ & & $\downarrow$ & \\
\hline Cardiac hypertrophy & & & $\uparrow$ & \\
\hline Renal hypertrophy & & $\uparrow$ & $\uparrow$ & $\uparrow$ \\
\hline Albuminuria & $\uparrow$ & $\uparrow \uparrow$ & $\uparrow \uparrow$ & $\uparrow \uparrow$ \\
\hline Glomerular Hypertrophy & & $\uparrow$ & $\uparrow$ & $\uparrow \uparrow$ \\
\hline Mesangial Expansion & & $\uparrow$ & & $\uparrow \uparrow$ \\
\hline Podocyte loss & $\uparrow$ & $\uparrow$ & $\uparrow$ & $\uparrow \uparrow$ \\
\hline Molecular Mechanisms of RAS & FEMALE & MALE & FEMALE & MALE \\
\hline Renal Agt & $\uparrow$ & & $\uparrow \uparrow$ & $\uparrow$ \\
\hline Renal Ren & $\downarrow$ & $\downarrow$ & $\downarrow$ & $\downarrow \downarrow$ \\
\hline Renal ACE & $\downarrow$ & $\downarrow$ & $\downarrow$ & $\downarrow \downarrow$ \\
\hline
\end{tabular}

Fig. 7 Proposed summary for the sex dimorphism and role of ACE2 in DN with and without ANGII hypertension. For each parameter, one arrow ( $\uparrow$ or $\downarrow$ ) indicates increased or decreased values as compared to the "reference value" of each sex, which corresponds to the WTCONT-SHAM-operated group. Two arrows indicate a more accentuated change. In ACE2KO-DB-ANGII females, overexpression of cortical AGT may contribute to higher activation of the endogenous RAS and, in consequence, increased production of intrarenal ANGII. Therefore, detrimental effects of exogenous ANGII may be enhanced by endogenous ANGII activity, leading to cardiac, renal, and glomerular hypertrophy, as well as more accentuated hypertension and albuminuria, as compared to the WT group. In ACE2KO-DB-ANGII males, glomerular alterations (namely glomerular hypertrophy, mesangial expansion, and podocyte loss) may be mostly ascribed to the actions of exogenous ANGII, as they presented lower cortical AGT levels than females, as well as a more significant negative feedback loop regulation in terms of reduced expression of renin and ACE, suggesting decreased formation of endogenous ANGII. GFR glomerular filtration rate, ACE2KO Ace 2 knockout, Agt angiotensinogen, ANGII angiotensin, ACE angiotensin-converting enzyme, Ren renin

and hypertensive female rats showed increased renal AGT as compared to males [33]. In this sense, augmented AGT led to increased BP in other hypertensive models $[65,66]$. It is known that increased BP synergizes with higher renal ANGII to stimulate AGT production and exert greater renal injury [65]. We speculate that ANGII-infused ACE2KO diabetic females entered the vicious circle of increasing AGT cleavage to ANGII, then increasing SBP and AGT levels, in which AGT stimulated hypertension, and vice versa. With our findings, we demonstrate a link between sex and the crosstalk of RAS components, hypertension and glomerular injury in T1DM, and confirm that ANGII plays a key role on this sex dimorphism. A better understanding of these connections will help to design more specific therapies to prevent DN through RAS modulation.

Regarding renal fibrosis, as expected ANGII administration to WT and diabetic groups stimulated cortical $T g f b l$ levels. In agreement, ANGII up-regulated TGF- $\beta 1$ in different cell lines such as smooth muscle and renal cells [7]. When ANGII was given to male rats under high-salt diet, fibrosis was exacerbated in the glomeruli and the interstitium [67]. A different pattern was observed in our 
diabetic ACE2KO groups, where ANGII reduced $T g f b l$ and Coll $\alpha 2$, especially in males. We speculate that ACE2 deficiency promotes a series of events in the kidney, including a deregulation of RAS involving a reduction in renin and ACE expression, as an attempt to compensate ANGII-mediated fibrosis [68].The activation of the immune system also contributes to the pathogenesis of hypertension and DN. This process involves many cytokines such as MCP1 [69]. We showed a proinflammatory effect of ANGII, as renal Mcpl was increased in infused mice. Interestingly, ACE2KO-DB + ANGII males showed significantly higher Mcpl levels than the SHAM group, indicating a more severe inflammation that may be ascribed to the greater alteration of RAS. It is known that altered levels of ANG peptides lead to inflammation [70, 71]. We now report that this inflammation is sex-dependent.

With this work we demonstrate that the direct effects of ANGII on hypertension and kidney disease in vivo are accentuated by ACE2 deficiency and diabetes, and strongly influenced by sex. In non-diabetic WT mice, ANGII promoted hypertension and cardiac hypertrophy in males, which also showed a greater decrease in GFR than females. In diabetic WT animals, ANGII administration was associated to a more marked albuminuria, glomerular hypertrophy, and mesangial expansion in males than in females (Fig. 7). ACE2 deficiency accentuated ANGII-induced hypertension and albuminuria in diabetic females, whereas in males accentuated glomerular lesions, namely glomerular hypertrophy, mesangial expansion, and podocyte loss. At the molecular level, ANGII induced a greater downregulation of $\mathrm{ACE}$ in $\mathrm{ACE} 2 \mathrm{KO}$ diabetic males, indicating a sex-specific ANGII-mediated crosstalk between ACE2 and ACE (Fig. 7). Our results thus indicate that sex differences in ANGII-related actions in hypertension and DN are ascribed, at least partially, to a sex-specific imbalance of RAS and a differential activation of its ACE2-related and ACE-related compensatory mechanisms. These mechanisms would include the negative feedback regulation of renal renin as an attempt to prevent the development of fibrosis and apoptosis under exposure to hyperglycemia and/or ANGII. Future studies targeting the ANGII axis in hypertension and DN according to sex differences will be of great interest, and potentially exert an impact in the nephrology field with the development of sex-directed therapies.

Acknowledgements We thank Dr. Susan B. Gurley for kindly supplying Ace 2 knockout mice. We also thank Marta Rebull, Joan Vilà, and Ester Aguado for their technical assistance. Finally, we thank Sergi Mojal for his support on statistical analysis.

Funding This work has been supported by grants from Fondo de Investigacion Sanitaria-Instituto Carlos III-FEDER (ISCIII-FEDER PI13/00598); Fondo de Investigacion Sanitaria-Instituto Carlos III-
FEDER (ISCIII-FEDER PI14/00557); and Red de Investigacion Renal, Fondo de Investigacion Sanitaria-Instituto Carlos III, Subprograma RETICS (RD16/0009/0013_ISCIII-RETICS REDinREN).

Author contributions Participated in research design: Sergi ClotetFreixas, Maria Jose Soler, Julio Pascual, and Marta Riera. Conducted experiments: Sergi Clotet-Freixas, Vanesa Palau, Lidia Anguiano, and Marta Riera. Performed data analysis: Sergi Clotet-Freixas, Maria Jose Soler, Javier Gimeno, and Marta Riera. Wrote or contributed to the writing and editing of the manuscript: Sergi Clotet-Freixas, Maria Jose Soler, Ana Konvalinka, Julio Pascual, and Marta Riera.

Conflict of interest The authors declare that they have no conflict of interest.

\section{References}

1. Caramori ML, Parks A, Mauer M. Renal lesions predict progression of diabetic nephropathy in type 1 diabetes. J Am Soc Nephrol. 2013;24(7):1175-81.

2. de Boer IH, Rue TC, Hall YN, Heagerty PJ, Weiss NS, Himmelfarb J. Temporal trends in the prevalence of diabetic kidney disease in the United States. JAMA . 2011;305(24):2532-9.

3. Reidy K, Kang HM, Hostetter T, Susztak K. Molecular mechanisms of diabetic kidney disease. J Clin Invest. 2014;124 (6):2333-40.

4. Dunlop M. Aldose reductase and the role of the polyol pathway in diabetic nephropathy. Kidney Int Suppl. 2000;58 Suppl 77: S3-S12.

5. Haneda M. Overview of glucose signaling in mesangial cells in diabetic nephropathy. J Am Soc Nephrol. 2003;14(5):1374-82.

6. Kawanami D, Matoba K, Utsunomiya K, Signaling pathways in diabetic nephropathy. Histol Histopathol. 2016;31:1059-67. https://doi.org/10.14670/HH-11-777.

7. Wolf G. Renal injury due to renin-angiotensin-aldosterone system activation of the transforming growth factor-b pathway. Kidney Int. 2006;70:1914-9.

8. Yoo T-H, Li J-J, Kim J-J, et al. Activation of the renin-angiotensin system within podocytes in diabetes. Kidney Int. 2007;71(10):1019-27.

9. Pendergrass KD, Averill DB, Ferrario CM, Diz DI, Chappell MC. Differential expression of nuclear AT1 receptors and angiotensin II within the kidney of the male congenic mRen2. Lewis rat. Am J Physiol Ren Physiol. 2006;290(6):F1497-1506.

10. Mehta PK, Griendling KK. Angiotensin II cell signaling: physiological and pathological effects in the cardiovascular system. Am J Physiol Cell Physiol. 2007;292(1):C82-97.

11. Wolf G. New insights into the pathophysiology of diabetic nephropathy: from haemodynamics to molecular pathology. Eur $\mathrm{J}$ Clin Invest. 2004;34(12):785-96.

12. Siragy HM. Angiotensin II compartmentalization within the kidney: effects of salt diet and blood pressure alterations. Curr Opin Nephrol Hypertens. 2006;15(1):50-53.

13. Porpino SKP, Zollbrecht C, Peleli M, et al. Nitric oxide generation by the organic nitrate NDBP attenuates oxidative stress and angiotensin II-mediated hypertension. $\mathrm{Br} \quad \mathrm{J}$ Pharmacol. 2016;173:2290-302.

14. Rüster C, Wolf G, Angiotensin II as a morphogenic cytokine stimulating renal fibrogenesis. J Am Soc Nephrol. 2011;22 (7):1189-99. https://doi.org/10.1681/ASN.2010040384.

15. Zhang L, Ren Z, Yang Q, Ding G. Csk regulates angiotensin IIinduced podocyte apoptosis. Apoptosis. 2016;21(7):846-55.

16. Jennings BL, Anderson LJ, Estes AM, et al. Involvement of cytochrome P-450 1B1 in renal dysfunction, injury, and inflammation associated with angiotensin II-induced hypertension in 
rats. AJP Ren Physiol. 2012;302(4):F408-20. https://doi.org/10. 1152/ajprenal.00542.2011.

17. Liao T-D, Yang X-P, Liu Y-H, et al. Role of inflammation in the development of renal damage and dysfunction in angiotensin IIinduced hypertension NIH Public Access. Hypertension. 2008;52 (2):256-63.

18. Clotet S, Soler MJ, Rebull M, et al. Gonadectomy prevents the increase in blood pressure and glomerular injury in angiotensinconverting enzyme 2 knockout diabetic male mice. Effects on renin-angiotensin system. J Hypertens. 2016;34(9):1752-65.

19. Nadarajah R, Milagres R, Dilauro $M$, et al. Podocyte-specific overexpression of human angiotensin-converting enzyme 2 attenuates diabetic nephropathy in mice. Kidney Int. 2012;82 (3):292-303.

20. Oudit GY, Liu GC, Zhong J, et al. Human recombinant ACE2 reduces the progression of diabetic nephropathy. Diabetes. 2010;59(2):529-38.

21. Fernandez-Fernandez B, Ortiz A, Gomez-Guerrero C, Egido J. Therapeutic approaches to diabetic nephropathy--beyond the RAS. Nat Rev Nephrol. 2014;10(6):325-46. https://doi.org/10. 1038/nrneph.2014.74.

22. Locatelli F, Del Vecchio L, Cavalli A. Inhibition of the renin-angiotensin system in chronic kidney disease: a critical look to single and dual blockade. Nephron Clin Pract. 2009;113(4): c286-93.

23. Cherney DZI, Sochett EB, Miller JA. Gender differences in renal responses to hyperglycemia and angiotensin-converting enzyme inhibition in diabetes. Kidney Int. 2005;68(4):1722-8.

24. Miller JA, Cherney DZ, Duncan JA, et al. Gender differences in the renal response to renin-angiotensin system blockade. J Am Soc Nephrol. 2006;17(9):2554-60.

25. Sullivan JC. Sex and the renin-angiotensin system: inequality between the sexes in response to RAS stimulation and inhibition. Am J Physiol Regul Integr Comp Physiol. 2008;294(4):R1220-6.

26. Clotet S, Riera M, Pascual J, Soler MJ. RAS and sex differences in diabetic nephropathy. Am J Physiol Ren Physiol. 2016. https:// doi.org/10.1152/ajprenal.00292.2015.

27. Becker JB, Koob GF. Sex differences in animal models: focus on addiction. Pharmacol Rev. 2016;68(2):242-63.

28. Guizzetti M, Davies DL, Egli M, et al. Sex and the lab: an alcoholfocused commentary on the NIH initiative to balance sex in cell and animal studies. Alcohol Clin Exp Res. 2016;40(6):1182-91.

29. Joel D, Kaiser A, Richardson SS, Ritz SA, Roy D, Subramaniam B. A discussion on experiments and experimentation: NIH to balance sex in cell and animal studies. Catal Fem Theory Technosci. 2015;1:1-12.

30. Fischer M, Baessler A, Schunkert H. Renin-angiotensin system and gender differences in the cardiovascular system. Cardiovasc Res. 2002;53(3):672-7.

31. Abbate R, Mannucci E, Cioni G, Fatini C, Marcucci R. Diabetes and sex: from pathophysiology to personalized medicine. Intern Emerg Med. 2012;7 Suppl. 3:215-9.

32. de Alencar Franco Costa D, Todiras M, Campos LA, Cipolla-Neto J, Bader M, Baltatu OC. Sex-dependent differences in renal angiotensinogen as an early marker of diabetic nephropathy. Acta Physiol (Oxf). 2015;213(3):740-6. https://doi.org/10.1111/apha. 12441.

33. Yamaleyeva LM, Gilliam-Davis S, Almeida I, et al. Differential regulation of circulating and renal ACE2 and ACE in hypertensive mRen2.Lewis rats with early-onset diabetes. Am J Physiol Ren Physiol. 2012;302(11):F1374-84.

34. Lim YK, Retnam L, Bhagavath B, Sethi SK, bin Ali A, Lim SK. Gonadal effects on plasma ACE activity in mice. Atherosclerosis. 2002;160(2):311-6.

35. Liu J, Ji H, Zheng W, et al. Sex differences in renal angiotensin converting enzyme 2 (ACE2) activity are 17 $\beta$-oestradiol- dependent and sex chromosome-independent. Biol Sex Differ. 2010;1(1):6. https://doi.org/10.1186/2042-6410-1-6.

36. Wysocki J, Ye M, Soler MJ, et al. ACE and ACE2 activity in diabetic mice. Diabetes. 2006;55(7):2132-9.

37. Riera M, Marquez E, Clotet S, et al. Effect of insulin on ACE2 activity and kidney function in the non-obese diabetic mouse. PLoS ONE. 2014;9(1):1-11.

38. Riera M, Anguiano L, Clotet S, et al. Paricalcitol modulates ACE2 shedding and renal ADAM17 in NOD mice beyond proteinuria. Am J Physiol Ren Physiol. 2016;310(6):F534-46.

39. Anderson S, Jung FF, Ingelfinger JR. Renal renin-angiotensin system in diabetes: functional, immunohistochemical, and molecular biological correlations. Am J Physiol. 1993;265(4, Part 2): F477-86. https://doi.org/10.1152/ajprenal.1993.265.4.F477.

40. Neugarten J, Golestaneh L. Gender and the prevalence and progression of renal disease. Adv Chronic Kidney Dis. 2013;20 (5):390-5. https://doi.org/10.1053/j.ackd.2013.05.004.

41. Clotet S, Riera M, Pascual J, Soler MJ. RAS and sex differences in diabetic nephropathy. Am J Physiol Renal Physiol. 2016;310: F945-57. https://doi.org/10.1152/ajprenal.00292.2015.

42. Pendergrass KD, Pirro NT, Westwood BM, Ferrario CM, Brosnihan $\mathrm{KB}$, Chappell MC. Sex differences in circulating and renal angiotensins of hypertensive mRen(2). Lewis but not normotensive Lewis rats. Am J Physiol Heart Circ Physiol. 2008;295(1): H10-20.

43. Ye M, Wysocki J, Naaz P, Salabat MR, LaPointe MS, Batlle D. Increased ACE 2 and decreased ACE protein in renal tubules from diabetic mice: a renoprotective combination? Hypertension. 2004;43(5):1120-5.

44. Fang F, Bae E-H, Hu A, et al. Deletion of the gene for adiponectin accelerates diabetic nephropathy in the Ins2 (+/C96Y) mouse. Diabetologia. 2015;58(7):1668-78.

45. Liu GC, Fang F, Zhou J, et al. Deletion of p47phox attenuates the progression of diabetic nephropathy and reduces the severity of diabetes in the Akita mouse. Diabetologia. 2012;55(9):2522-32.

46. Wong DW, Oudit GY, Reich $\mathrm{H}$, et al. Loss of angiotensinconverting enzyme-2 (Ace2) accelerates diabetic kidney injury. Am J Pathol. 2007;171(2):438-51.

47. Soler MJ, Wysocki J, Ye M, Lloveras J, Kanwar Y, Batlle D. ACE2 inhibition worsens glomerular injury in association with increased ACE expression in streptozotocin-induced diabetic mice. Kidney Int. 2007;72(5):614-23. https://doi.org/10.1038/sj. ki.5002373.

48. Shiota A, Yamamoto K, Ohishi M, et al. Loss of ACE2 accelerates time-dependent glomerular and tubulointerstitial damage in streptozotocin-induced diabetic mice. Hypertens Res. 2010;33 (4):298-307.

49. Tikellis C, Bialkowski K, Pete J, et al. ACE2 deficiency modifies renoprotection afforded by ACE inhibition in experimental diabetes. Diabetes. 2008;57(4):1018-25.

50. Johnson RJ, Alpers CE, Yoshimura A, et al. Renal injury from angiotensin II-mediated hypertension. Hypertens (Dallas, Tex 1979). 1992;19:464-74. http://www.ncbi.nlm.nih.gov/pubmed/ 1568765. Accessed 28 May 2017.

51. Ruiz-Ortega M, Ruperez M, Esteban V, et al. Angiotensin II: a key factor in the inflammatory and fibrotic response in kidney diseases. Nephrol Dial Transplant. 2006;21(1):16-20.

52. Wiecek A, Chudek J, Kokot F. Role of angiotensin II in the progression of diabetic nephropathy-therapeutic implications. Nephrol Dial Transplant. 2003;18(90005):16v-20. https://doi.org/ 10.1093/ndt/gfg1036.

53. Gurley SB, Allred A, Le $\mathrm{TH}$, et al. Altered blood pressure responses and normal cardiac phenotype in ACE2-null mice. $\mathrm{J}$ Clin Invest. 2006;116(8):2218-25.

54. Jin H-Y,Song B,Oudit GY, et al. ACE2 deficiency enhances angiotensin II-mediated aortic profilin-1 expression, inflammation 
and peroxynitrite production. PLoS ONE. 2012;7(6):e38502. http://10.1371/journal.pone.0038502.

55. Crowley SD, Gurley SB, Herrera MJ, et al. Angiotensin II causes hypertension and cardiac hypertrophy through its receptors in the kidney. Proc Natl Acad Sci USA. 2006;103(47):17985-90.

56. Nicholas SB, Mauer M, Basgen JM, Aguiniga E, Chon Y. Effect of angiotensin II on glomerular structure in streptozotocin-induced diabetic rats. Am J Nephrol. 2004;24(5):549-56.

57. Vera T, Stec DE. Moderate hyperbilirubinemia improves renal hemodynamics in ANGII-dependent hypertension. Am J Physiol Regul Integr Comp Physiol. 2010;299(4):R1044-R1049. https:// doi.org/10.1152/ajpregu.00316.2010.

58. Sochett EB, Cherney DZI, Curtis JR, Dekker MG, Scholey JW, Miller JA. Impact of renin-angiotensin system modulation on the hyperfiltration state in type 1 diabetes. J Am Soc Nephrol. 2006;17(6):1703-9.

59. Phie J, Haleagrahara N, Newton P, et al. Prolonged subcutaneous administration of oxytocin accelerates angiotensin II-induced hypertension and renal damage in male rats. PLoS ONE. 2015;10(9): 0138048.

60. Xue B, Zhang Z, Beltz TG, Guo F, Hay M, Johnson AK. Estrogen regulation of the brain renin-angiotensin system in protection against angiotensin II-induced sensitization of hypertension. AJP Heart Circ Physiol. 2014;307(2):H191-8.

61. Elmarakby AA, Bhatia K, Crislip R, Sullivan JC, Hemodynamic responses to acute angiotensin II infusion are exacerbated in male versus female spontaneously hypertensive rats. Physiol Rep. 2016;4(1):e12677. https://doi.org/10.14814/phy2.12677.

62. Toering TJ, van der Graaf AM, Visser FW, et al. Gender differences in response to acute and chronic angiotensin II infusion: a translational approach. Physiol Rep. 2015;3(7):e12434.

63. Saez F, Reverte V, Paliege A, et al. Sex-dependent hypertension and renal changes in aged rats with altered renal development.
AJP Ren Physiol. 2014;307(4):F461-70. https://doi.org/10.1152/a jprenal.00198.2014.

64. Yamaleyeva LM, Gilliam-Davis S, Almeida I, Brosnihan KB, Lindsey SH, Chappell MC. Differential regulation of circulating and renal ACE2 and ACE in hypertensive mRen2.Lewis rats with early-onset diabetes. AJP Ren Physiol. 2012;302(11):F1374-84.

65. Shao W, Miyata K, Katsurada A, et al. Increased angiotensinogen expression, urinary angiotensinogen excretion and tissue injury in non-clipped kidneys of 2-kidney 1-clip hypertensive rats. Am J Physiol Renal Physiol. 2016;311(2):F278-90.

66. Yanes LL, Sartori-Valinotti JC, Iliescu R, et al. Testosteronedependent hypertension and upregulation of intrarenal angiotensinogen in Dahl salt-sensitive rats. Am J Physiol Ren Physiol. 2009;296(4):F771-9.

67. Lara LS, Mccormack M, Semprum-Prieto LC, et al. AT 1 receptor-mediated augmentation of angiotensinogen, oxidative stress, and inflammation in ANGII-salt hypertension. Am J Physiol Renal Physiol. 2012;302(1):F85-94.

68. Ruiz-Ortega M, Rupérez M, Esteban V, et al. Angiotensin II: A key factor in the inflammatory and fibrotic response in kidney diseases. Nephrol Dial Transplant. 2006;21(1):16-20. https://doi. org/10.1093/ndt/gfi265.

69. Carr MW, Roth SJ, Luther E, Rose SS, Springer TA. Monocyte chemoattractant protein 1 acts as a T-lymphocyte chemoattractant. Proc Natl Acad Sci USA. 1994;91(9):3652-6.

70. Benigni A, Cassis P, Remuzzi G. Angiotensin II revisited: new roles in inflammation, immunology and aging. EMBO Mol Med. 2010;2(7):247-57.

71. Xu Z, Li W, Han J, et al. Angiotensin II induces kidney inflammatory injury and fibrosis through binding to myeloid differentiation protein-2 (MD2). Sci Rep. 2017;7:44911. 